\title{
EFICÁCIA DE VERMÍFUGOS À BASE DE AVERMECTINAS E MILBEMICINAS UTILIZADOS HÁ CINCO ANOS EM UMA CRIAÇÃO DE EQÜINOS
}

\author{
EFFICACY OF AVERMECTINS AND MILBEMICINS ANTHELMINTICS \\ DERIVATIVES BEING USED FOR FIVE YEARS IN AN EQUINE FARM
}

\author{
Carlos Eduardo Wayne Nogueira ${ }^{1}$ Alzira Pacheco de Lima ${ }^{2}$ Jerônimo Ruas ${ }^{3}$ \\ Alexandre de Leon Jardim ${ }^{4}$
}

\section{RESUMO}

Avaliou-se a eficácia do controle parasitário com anti-helmínticos $(A H)$ de largo espectro usados há mais de cinco anos, em um plantel eqüino da raça puro-sangue inglês, sob manejo semi-intensivo. Os animais foram tratados com Ivermectin Eqvalan ${ }^{\circledR}$ ) e Moxidectin (Equest ${ }^{\circledR}$ ), por via oral. Durante o estudo, o número de ovos por grama de fezes (opg) manteve-se zero na maioria dos animais.

Palavras-chave: anti-helmínticos, vermífugos, ivermectin, moxidectin, eqüinos.

\section{SUMMARY}

The efficacy of parasite control with broad spectrum anthelmintics, used for over five years on a Thoroughbred herd was evaluated. The animals were kept on semi-intensive pasture regimen. During this study the horses received Ivermectin $\left(\right.$ Eqvalan $\left.^{\circledR}\right)$ and Moxidectin $\left(\right.$ Equest $\left.^{\circledR}\right)$; both treatments were given orally. The epg number was zero for most animals troughout the trial.

Key words: anthelmintics, ivermectin, moxidectin, horses.
Segundo KLEI (1997) com o controle eficaz de parasitas Strongylus sp em eqüinos, através de antiparasitários altamente efetivos, passou-se a dar mais atenção aos ciatostomíneos. Estes helmintos provocam cólica, têm impacto negativo no desenvolvimento, causando perda na performance geral e são responsáveis pela ciatostomíase larval, condição associada ao aparecimento súbito de diarréia, queda no estado geral do animal e, em alguns casos, morte. De acordo com este autor, o uso exagerado de antihelmínticos tem potencial de indução de raças de ciatostomíneos resistentes a esses fármacos. Os programas vigorosos de controle parasitário, que iniciam antes de 6 a 8 semanas de idade, podem aumentar a duração da infecção por Parascaris equorum e Strongyloides westeri. Ele ressaltou também que os programas de controle que excluem ou minimizam a infecção reduzem o

\footnotetext{
${ }^{1}$ Médico Veterinário, Mestre, Professor Assistente, Departamento de Clínica Veterinária, Universidade Federal de Pelotas (UFPEL), Campus Universitário, 96100-900, Pelotas, RS. E-mail: nogueira@ufpel.tche.br. Autor para correspondência.

${ }^{2}$ Médico Veterinário, Doutor, Professor Adjunto, Departamento de Clínica Veterinária, UFPEL.

${ }^{3}$ Médico Veterinário, Mestre, Técnico Nível Superior, Laboratório Regional de Diagnóstico, Faculdade de Veterinária, UFPEL.

${ }^{4}$ Médico Veterinário autônomo, Bagé, RS.
} 
desenvolvimento de imunidade e aumentam o risco de doença associada à parasitose, quando os animais são expostos a um forte desafio parasitário.

Ivermectin e pirantel são ainda efetivos contra ciatostomíneos, mas não têm eficácia significativa contra larvas $\mathrm{L}_{3}$ inibidas e estádios iniciais de $\mathrm{L}_{4}$ na mucosa, em doses terapêuticas (EYSKER $\boldsymbol{e t}$ al., 1992) ou em doses elevadas (KLEI et al., 1993). Isto destaca a importância dos programas estratégicos de controle anti-helmíntico para prevenir a contaminação elevada das pastagens, com o subseqüente alto número de larvas inibidas na mucosa.

Neste estudo, utilizou-se um plantel de 200 eqüinos da raça puro-sangue inglês, constituído por 80 éguas prenhes, 20 éguas vazias, 56 potros de sobreano e 44 potros neonatos.

Os animais foram mantidos em um haras na região de Bagé-RS, com 380 hectares, divididos em 40 piquetes, com manejo semi-intensivo. As amostras utilizadas neste experimento foram obtidas de $30 \%$ dos equiinos do plantel, os quais foram divididos conforme a idade. As coletas nos neonatos (de 1 a 190 dias de idade) foram realizadas com intervalos de 15 dias. Em 30\% das éguas, fez-se uma coleta de amostras no início e outra no final do experimento. $\mathrm{O}$ mesmo procedimento foi usado para os potros entre 12 e 18 meses de idade. As fezes foram obtidas diretamente da ampola retal e as contagens de opg em amostras pareadas foram feitas segundo a técnica de GORDON \& WHITLOCK (1939), modificada.

O manejo antiparasitário no haras, nos últimos 5 anos, foi baseado na aplicação de ivermectin $\left(\right.$ Eqvalan $^{\circledR}$ ) ou moxidectin (Equest ${ }^{\circledR}$ ) a cada 60 dias, em todos os eqüinos após 12 meses de idade, independente da infecção. Durante o experimento, manteve-se este esquema. Entretanto, as éguas foram tratadas com anti-helmíntico à base de milbemicina no $5^{\underline{0}}$ dia após o parto, retomando-se o manejo habitual em 90 dias. Os neonatos foram divididos em 2 grupos, dos quais um recebeu antihelmíntico com intervalos de 90 dias e o outro, composto de 4 animais, serviu como controle não tratado. A análise estatística dos dados foi realizada através do teste Qui-quadrado.

Observou-se que, das 116 amostras de fezes coletadas de potros neonatos com idade entre 15 e 90 dias, período no qual os animais ainda estavam fora do tratamento anti-helmíntico, três potros de um total de 28 apresentaram infecção por gêneros da Superfamília Strongyloidea (Tabela 1). Comparando-se com dados da literatura (TAYLOR \& KENNY, 1995; DEMEULENAERE $\boldsymbol{e t}$ al., 1997), apenas um dos potros apresentou número de opg
Tabela 1 - Números de ovos por grama de fezes (opg), obtidos em neonatos eqüinos, em um plantel tratado com os antihelmínticos ivermectin e moxidectin, por um período de cinco anos.

\begin{tabular}{lcc}
\hline Idade (dias) & No de amostras & Nível de infecção (opg) \\
\hline $15-30$ & 25 & 00 \\
& 1 & $250^{* *}$ \\
& 1 & $125^{* *}$ \\
$31-45$ & 1 & $50^{*}$ \\
& 20 & 00 \\
$46-60$ & 1 & $375^{* *}$ \\
& 1 & $500^{*}$ \\
$61-75$ & 21 & 00 \\
& 1 & $125^{* *}$ \\
$76-90$ & 18 & 00 \\
& 1 & $125^{* *}$ \\
$91-105$ & 1 & $50^{* *}$ \\
$106-120$ & 23 & 00 \\
& 1 & $25 c^{* *}$ \\
$121-135$ & 14 & 00 \\
& 13 & 00 \\
$136-145$ & 1 & $250 c^{* *}$ \\
$146-160$ & 15 & 00 \\
$161-175$ & 1 & $75 c^{* *}$ \\
$176-190$ & 15 & 00 \\
\hline & 14 & 00 \\
& 16 & 00 \\
& 15 & 00 \\
\hline & &
\end{tabular}

* Ovos de Strongyloides spp

** Ovos pertencentes à Superfamília Strongyloidea

ç Potro do grupo controle

compatível com a necessidade de tratamento com anti-helmíntico.

Somente potros do grupo controle apresentaram opg positivo entre os dias 76 e 135 do experimento, embora com contagem aquém dos limites que determinam tratamento. Após este período, até o final do estudo, as amostras de fezes obtidas de neonatos foram negativas para a presença de ovos de helmintos. As contagens de opg realizadas em amostras de fezes das éguas, bem como dos potros de sobreano, num total de $32 \mathrm{em}$ cada categoria, foram positivas apenas em 5 potros. Através da análise estatística pelo teste Quiquadrado, observou-se que não houve diferença significativa entre os resultados obtidos nos diferentes períodos do experimento.

O número de opg próximo a zero em todas as categorias é compatível com observações de TAYLOR \& KENNY (1995) e DEMEULENAERE et al. (1997). Porém, contrasta com os dados de VIERA \& NOGUEIRA (1997) e GOMES et al. (1999). A eliminação eventual de ovos de Strongyloides por alguns potros está de acordo com os resultados de BEELITZ et al. (1995). 
Neste programa de controle parasitário sem rotação de princípios ativos, não foi constatado o aparecimento de resistência, dado já salientado por KLEI (1997) em eqüinos tratados com ivermectin.

\section{REFERÊNCIAS BIBLIOGRÁFICAS}

BEELITZ, P., RIEDER, N., GOTHE, R. Zur Befallshafigkeit von Strongyloides westeri bei Pferdefohlen aus Zuchtbetrieben mit und ohne Anthelminthika Prophylaxe in Oberbayern. Pferdeheilkunde, v.11, n.3, p.207-211, 1995.

DEMEULENAERE, D., VERCRUYSSE, J., DORNY, P., et al. Comparative studies of ivermectin and moxidectin in the control of naturally acquired cyathostome infections in horses. Veterinary Record, v.141, p.383-386, 1997.

EYSKER, M., BOERSEMA, J.H., KOOYMAN, F.N.J. The effect of ivermectin treatment against inhibited early third stage, late third stage and fourth stage larvae and adult stages of the cyathostomes in Shetland ponies and spontaneous expulsion of these helminths. Veterinary Parasitology, v.42, n.3-4, p.295-302, 1992.
GOMES, T.L.S., MERCIER, P., WHITE, C.R. Avaliação da persistência da eficácia de dois anti-helmínticos orais para eqüinos criados a campo. A Hora Veterinária, v.18, n.108, p.57-61, 1999.

GORDON, H.M., WHITLOCK, H.V. A new tecnique for counting nematode eggs in sheep faeces. J Commonw Sci and Indust Organization, v.12, n.1, p.50-62, 1939.

KLEI, T.R. Parasite control programs. In: ROBINSON, N.E. Current therapy in equine medicine. Philadelphia : Saunders, 1997. v.4, p.709-712.

KLEI, T.R., CHAPMAN, M.R., FRENCH, D.D., et al. Evaluation of ivermectin at an elevated dose against encysted equine cyathostome larvae. Veterinary Parasitology, v.77, p.88-96, 1993.

TAYLOR, S.M., KENNY, J. Comparison of moxidectin with ivermectin and pyrantel embonate for reduction of faecal egg counts in horses. Veterinary Record, v.137, p.516-518, 1995.

VIEIRA, M.I.B., NOGUEIRA, C.E.W. Estudo comparativo da eficácia anti-helmíntica de distintos grupos químicos, no controle parasitário de eqüinos da raça Crioula. Ciência Rural, v.2, n.1, p.58-62, 1997. 